\title{
Practical Review and Evaluation on Parenting Education
}

\author{
Jewish Araneta-Merin \\ Cebu Normal University
}

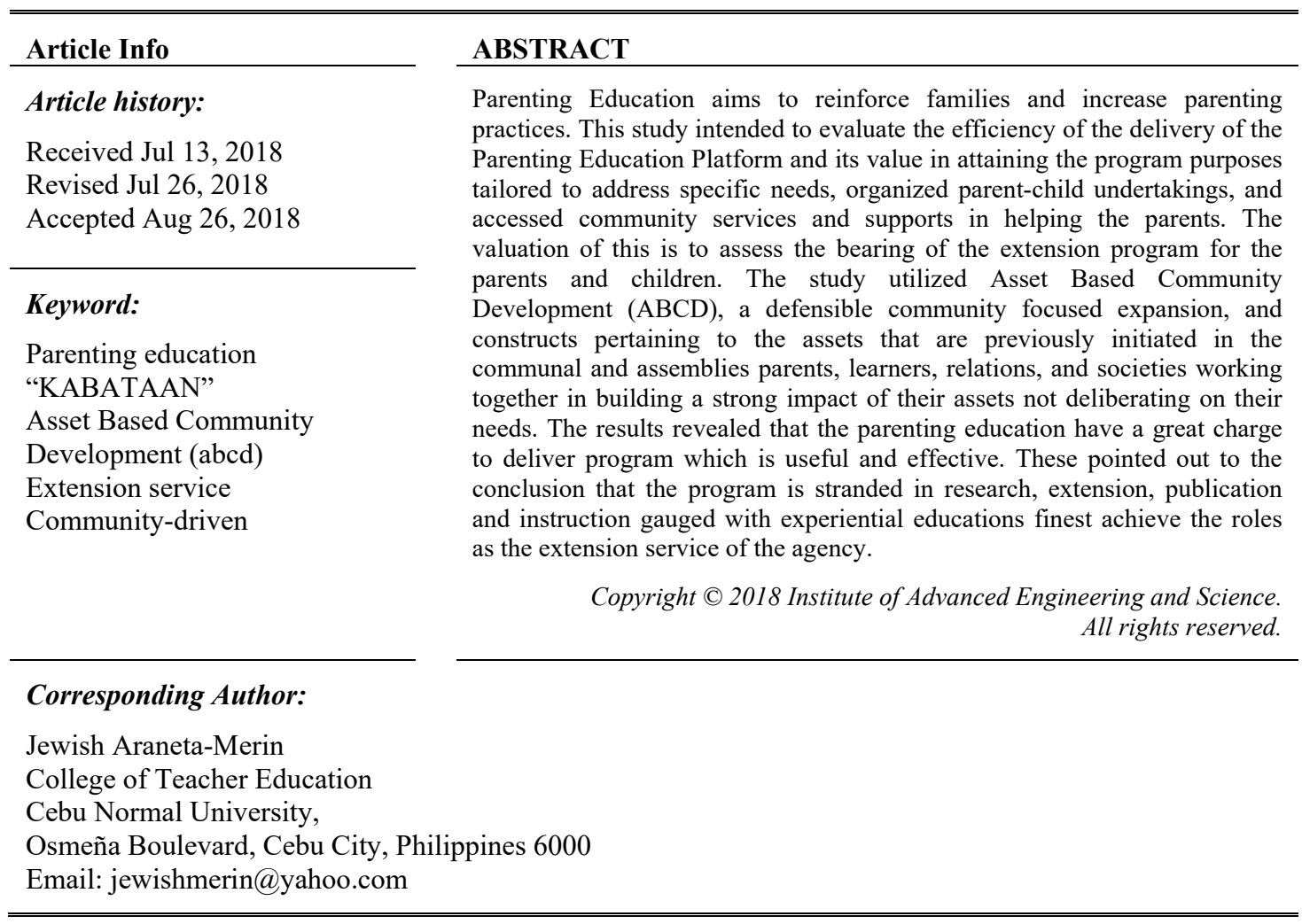

\section{INTRODUCTION}

In general, the parenting education programs desire to strengthen families and enhance parenting practices. The parental expectation is one of the facets in parent attachments that have large impact on learner's achievement. They carry out their best efforts when their parents await best. To bridge the disparity between the school environment and the home, the learning institution must build an effective connection by creating a collaborative and open partnership within the wider locale.

In view of the holistic expansion, in improving parental involvement in the upkeep, growth and development of the young learners, the UNICEF Philippines has printed the needed parent education materials to support such parental development.With the strengths in extension project mentioned however the program obstacles are the requirement to broaden coverage, lack of evaluations on changes in parental knowledge, attitude and practices and the lack of parental response and feedback (Al-Hassan 2009).

Nurturing each child shows a great role in acquiring developmentally seemly social and emotionalcapabilities, thus the many attributes of a young child's life in socio-emotional development of a preschool aged child impacts. The three types of parenting styles varies in guiding the child. Authoritative parents can be pliable but with the consistent rules. They incline to the advance clear guidelines and expectations for their children, while providing lots of nurturing and love. Usually, authoritarian parents are not as nurturing as the other two parenting styles however they associate affection with realization. They required extraordinary standards and strategies and conformity within. Lastly, parents who are permissive have little or no anticipations at all for their children because oftenly they view them as associates' and have few restrictions enforced. 
Since parents have the vital guidance beyond a child's day to day interfaces and goings-on, it is relevant to conceptualize the educational suggestions of parenting styles for it has a great impact on the child's socio-emotional development. As a foundation for relationship structure, the appropriate socioemotional skills therefore are looked-for. The parenting spheres, such as communication smartness, altitudes of receptiveness, and levels of mechanism are developed in combining one with the other in order to brand a personality's overall parenting style. Utmost parenting conduct is multidimensional and usually the parenting performs are typhically used in concurrence with one alternative. Thus, when understanding its' effects that parenting behavior has on child outcomes, the overall parenting style is to be considered (Perepletchikova \& Kazdin 2005).

Cebu Normal University Extension Programs address its mission in encompassing the three equally reinforcing drives: first is the transformative education that cultivates the creative thinking of the being who played a great role as leaders and members of the society; secondly is the infinite impact of the researches that investigates the boundaries of knowledge in education and contribute to improving communities; and lastly is to construct a resilient partnerships that cooperatively and innovatively cater the improvement between and among the gaps of the service communities.

\subsection{Background}

One of the extension projects of the foremost institution is Parenting Education of the College of Teacher Education. There were five extension workers functioning as a Team in facilitating the Parenting Education and finding out the Parenting Styles of the listed participants. The Extension professionals were responsible in making the Parenting Education Module which was copyrighted at IPP Intellectual Property Philippines. The members of the Team take turns in going to the Extension Sites namely Sitio Pilit and Sitio Bangbang of Barangay Nangka, Balamban Cebu. The project has fifty enrolled parents as beneficiaries. Using the Module as guide in the Project Implementation, the first batch of the Parenting program had a flourishing Culminating Activity last March 2016. The Parenting Team desired to evaluate the project and wished to expand the project in another extension sites. So this parenting education research is a great help in the future extension works.

The basis on choosing an eventful extension programs is for the professionals to adopt a parenting package that paramount to the clienteles' needs. A review and evaluation of the major Parenting Education of the College of Teacher Education curricula could possibly succor the parents and professionals in fulfilling the said extension program. The CTE's extension project which is Parenting Education, makes use of a multitude curricula, series of effective tasks, research-based thus, making it pressing for the Extension workers, parents and children in the rendered community. With assurance, it has prompted the researcher to look into the empirical evidence on program effectiveness. Thus this study is conducted.

\subsection{Objectives of the Study}

This study intends to appraise the expediency in the delivery of the Parenting Education Program and the innovations in attaining the program objectives tailored to address specific needs, organized parentchild activities, and accessed community services and supports in helping the parents in the community. The valuation is to assess the family and the interaction between the parents and the children with regards to the programs' impact.

\subsection{Short Literature Review}

For many years, many parental involvement researches were conducted and its effects to the educational arena. The uniqueness of this study however, is on the strong linkages between the educators and the identified parents of the chosen community is catered on strong partnership between educators to the identified parents in the chosen community and the sustenance of the said extension program when the proponents of the extension project moved from another extension site.

In view of the economist's mindset, parental involvement may be defined as the undeviating effort delivered by the parent for the proliferation on the academic outcomes of their children. This subtly defines to the function of the educational production and marks the parental involvement as one of its arguments (Avvisati et. al., 2010). Altschul (2012) mentioned that conferring to Sirin (2005), the family's socioeconomic status greatly influence on the children's academic performance. Thus, there is a substantial direct relationship between the parental connection and socio-economic status (Zedan, 2011). In the real scenario, those guardians/parents who have stable financial status can donate to the schools (Hodtuv, 2001). With this, there was an established positive communication amid the degree of the parents' contribution and their level of education.

In school, those parents who supported their children yield better in terms of academic activities because they are aware of what's going on in their educational endeavour. Of course if there is a deficiency

IJERE Vol. 7, No. 3, September 2018: $253-258$ 
of parental involvement then the success of the students' performance is critically unnatural. If there is no upkeep from the parents, then the students are stressed in terms of educational tasks (Wanke, 2008). According to Angion (2009), the involvement of parents is connected the attainment of the cognition, affection, verbal communication and socio-emotional escalation. Thus establish the fact that pupil's achievement in school is correlated to the attaching comportment of the parents. Desforges with Abouchaar (2003) quantified that there is a high level of attainment if there is parental engrossment.

The Stop, Think, Ask, Respond (STAR) program on parenting, established by Fox and Fox attempted to aid the parents of the young learners through a grounded project in the developmental and cognitive-behavioral theories and presents educational implication on how these principles of authoritative parenting as well as the research-based indication that parents and children sway one another in a reciprocal mode (Fox \& Nicholson, 2003).

Children's successful management in day's experiences can lead to the system in emotional competence. With these, it fixated on the aspects of using emotions to send and receive messages that are important to social interactions and is important as it plays a role in self-esteem. The parents can create a scenario of acceptance, reassurance, convenience that builds the childrens' self-esteem (Halberstadt, Denham \& Dunsmore, 2001).

The ways in which children's emotional competence is related to their social competence with peers as it is often overlapping between emotional competence and social competence, the latter is usually defining by one's social skills and peer status, whereas the former is focusing on more intrapersonal qualities, such as the ability to understand or produce appropriate emotion signals. Generally speaking, children are rated by both teachers and peers as more socially competent, those who are better able to manage their emotional displays and exhibit more positive affect. Thus, children learn the different rules and norms and apply it to the different everyday settings and adapt accordingly.

Another designed as the Nurturing Parenting Program on the basis of the prevention of empirically validated parental risk factors for abuse and neglect emphasizes the following seven principles from which to build warm and caring environments for children: feelings of attachment, empathy, nurturing oneself, gentle touch, discipline, expressing feelings, expectations, and self-worth (Bavolek, 2007).

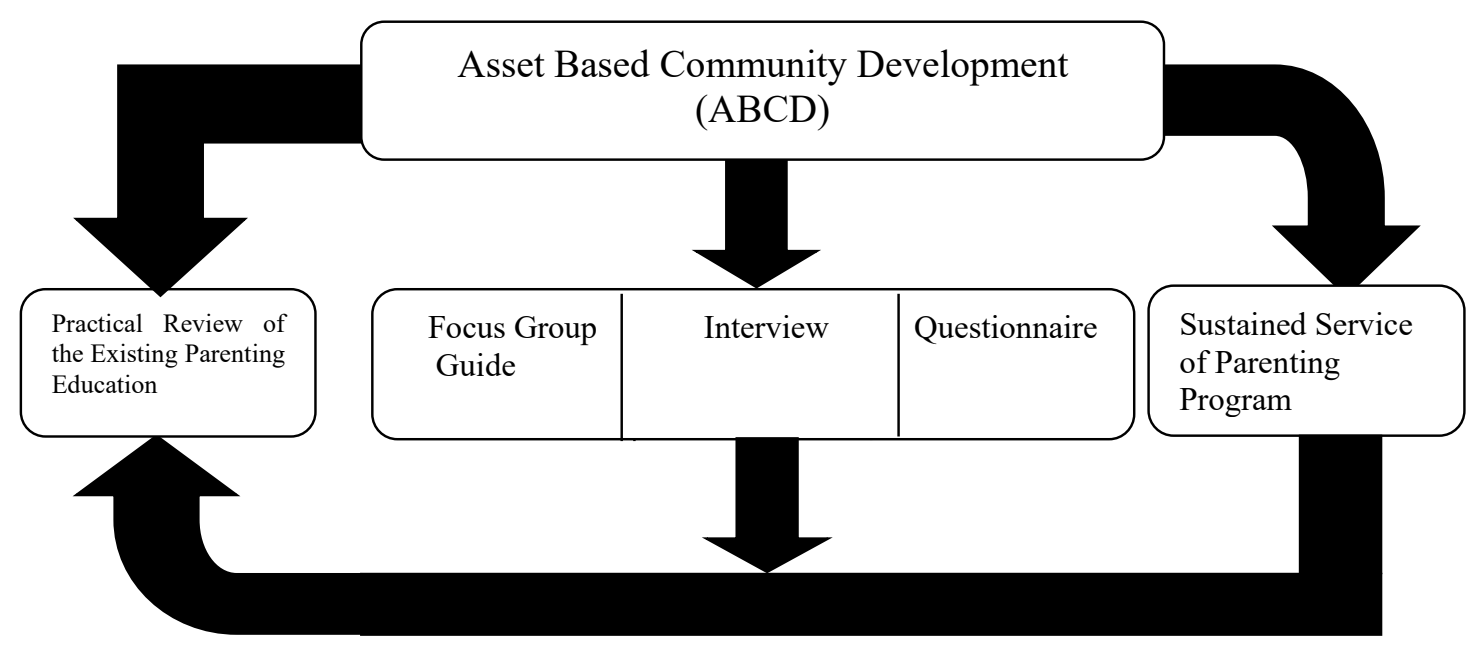

Figure 1. Framework of the Study

To achieve a better community development is the ultimate goal and framework for planning, evaluating and learning from community improvement interventions. This approach argues that the evaluation process is central to effective performance of the extension services conducted, and in community development activities, it should be facilitated within the communities themselves. The study utilized Asset Based Community Development (ABCD), a defensible community-driven expansion, and constructs the assets that are previously initiated in the communal and assemblies parents, learners, relations, and societies to come together to build on their assets- not deliberate on their needs. In this way, a shared view about what modification needs to take place within the service institution and how that will occur in the community can be developed. Each community has a distinctive set of skills and capacities to conduit for community 
development. The $\mathrm{ABCD}$ categorizes asset inventories into five groups namely interactions of parentslearners, associations, institutions, physical assets and connections.

A slot for Extension project of the faculty with the skillfulness to scrape together from all benchmark information those research or evidenced-based educational programs that are most plausible, dependable, and valuable. Implementation of the Extension Project can be a complex, and sometimes confusing, process. To evaluate with making implementation more approachable and practical, this cram has identified useful tools on key areas of interest to implementation in real world child and family service settings namely focus group guide, interviews and ABCD questionnaire to ensure the output's sustainability and accountability of the program.

\section{RESEARCH METHOD}

An initial step of the practical review is to evaluate the notional underpinnings of the standard of Parenting Education Program of the College of Teacher Education (CTE) by reviewing the program goals versus documenting the outcomes for which the program demonstrated practical support. In this case, it is to endow with research-based community information with the empirically implemented parenting education program. The interviews and focus group discussions data were analyzed qualitatively according to research questions and SWOT analysis (Strengths, Weaknesses, Opportunities, and Threats).

To address the need for careful evaluation of parenting program and its social impact, ABCD as a tool which is susceptible that looks with Parenting Education Program standard, in this act to provide research-based information versus the actual results of the parenting education program. This encourages those involved in community development, whether as funders, policymakers, administrators, extension workers, volunteers or community members, to clearly rate and evaluate about what they achieve and how they should go about it for sustaining the resources. The ABCD draws out strengths and successes in a community's shared history as its starting point for innovations of the society.

There are three criteria in order to evaluate the Parenting Program of the CTE and check the outcome goals of clientele needs and satisfaction. The first criterion is the most practical one -the inclination of the Parenting Program employed. Moreover to achieve the objectives of the evaluation, qualitative research was implemented. It consists of three focus groups and interviews which were organized with the Extension professionals, Extension Director and Vice President (Research, Extension and Publication) in assisting the efficiency of the extension program delivery and the appropriateness of the modular program design so as achieving the extension project objectives.

The second criterion is evidence/science-based. Science-based ratings ranged from zero (There was no clear evidence of support in the program) to five (An evidently successful extension program at work). In addition to the evaluation, is the focus group discussion and interviews were conducted to the participating Local Government Officials as partners to deliberate the sustainability factors affecting the program. The researcher employed a researcher-made unstructured interview guide to gather and collect data from the first person descriptions of the purposively selected respondents with regards to the success of the extension program. Unstructured interview was utilized to allow the discussion to cover areas in great detail and for the researcher to learn more about the parenting topics that the community wanted to have.

Third is the quality on program's effectiveness. The questionnaire is based on the satisfied clientele of $\mathrm{ABCD}$ downloaded in the internet. Some items of the tool in international measures were adapted, to evaluate parent's knowledge, skills, perceptions, and behaviors regarding child development, interaction with children, and discipline practices towards parenting skills.

The focus of this study is the social interactions as well as the population, is at the core of ABCD of this study includes the fifty parents listed as beneficiaries of the project. Thus the participating representative samples of Sitio Pilit and Sitio Bangbang of Barangay Balamban, Cebu. Therefore, assets of the families are treated as the means to mobilize though formal and informal interactions. The resources of creating efficient parenting styles of the community is practically applied to the social capital concept and treating these relationships as assets.

\section{RESULTS AND ANALYSIS}

With the Extension's mission - to target a research-based evidence and empirically employed parenting education program, the researcher was able to collate information about the effectiveness of the program.

IJERE Vol. 7, No. 3, September 2018: 253-258 


\subsection{Analysis of Parenting Education Program}

This ABCD framework exists to explicate desirable aspects of child, parent and family wellbeing. A comprehensive review of the evidence based to measure the level of effectiveness of the parenting education program. Table 1 shows how the program was evaluated following the three criteria in order to evaluate the Parenting Program of the CTE and the implementation strategies towards the clientele needs. The first criterion was a very practical one -the inclination of the Parenting Program used. It consists of three focus groups and interviews which were organized with the Extension professionals, Extension Director and Vice President (Research, Extension and Publication) to assess the efficiency of program delivery and the appropriateness of the program design in achieving its extension project objectives. The program was rated on each criterion using a Likert-type. Science-based ratings ranged from zero (there was no clear evidence of research support in the program) to five (an evidently successful extension program at work).

Table1. Summary of Parenting Program Ratings for Empirical Effectiveness

\begin{tabular}{llc}
\hline \multicolumn{1}{c}{$\begin{array}{c}\text { Parenting Program Name } \\
\text { (Target Audience) }\end{array}$} & \multicolumn{1}{c}{$\begin{array}{c}\text { Readiness of the Program } \\
\text { Effectiveness }\end{array}$} & $\begin{array}{c}\text { Recommended } \\
\text { Implementation }\end{array}$ \\
\hline $\begin{array}{l}\text { Parenting Education of the College of Teacher } \\
\begin{array}{l}\text { Education } \\
\text { (Parents of Children ages } 2 \text { to } 4 \text { years with the } \\
\text { learners in a different learning station) }\end{array}\end{array} \begin{array}{l}\text { The extension workers prepared 2 } \\
\text { modules; one for the parents and the } \\
\text { other one for the young learners } \\
\text { "KABATAAN" }\end{array}$ \\
\hline
\end{tabular}

Each numeral rating on a Likert-type gauge of the program was rated on each criterion with vibrant peculiarities between the categories. In the evaluation, the self-help modules about parent education and KABATAAN for young learners were generally usable in a series of the extension sessions. The Parenting Education, developed by the College of Teacher Education of the Cebu Normal University, helped the parents of young children to respond instead of retort to perplexing child's behavior. The parenting education program shows positive outcome records since the organized evaluators rated the program four out five as evidently extension program at work. It is grounded in one of the parenting programs in the child's developmental stages and behavioral theories and principles which were useful of parenting that parents and children influence one another in a reciprocal manner (Fox and Nicholson, 2003). Evaluation research on CTE Parenting Education while utilizing 15 two-hour sessions, longitudinal assessment and large sample sizes 25 parents in the morning session and the same number in another sitio of the same barangay represents as remarkable of the said extension. Firming family program cartels the responsible parents and the youthful children to have a productive family and build fortes.

The extension parenting program project addresses the school enthusiasm extents besides educational appeals profoundly in the expanse on the literacy. The topics in KABATAAN Module provide the necessary materials for the fifty young learners in the social and functional literacy skills in preparation of their formal Kindergarten schooling. Fay (2007) debates the love of learning in line for the socio-cognitive learning conceptual frameworks. It was definitely executed by the parent-educator implementers because it has been evaluated internally and the clientele are required to attend the scheduled sessions. One of the educators commented on the extension workers utmost desire to help the community and extend great services not only to the parents but also to the young minds.

The project includes a strong evaluation component. One of the evaluators mentioned on the effectiveness of the program in refining the parents' knowledge, skills, attitudes and values on confidence, resourcefulness and coping skills. Another educator revealed on encouraging a safe and low encounter of fights within the neighboorhood environment in the family which one of the barangay officials affirmed of the less neighboring conflicts on child development instead the identified sitios/ places upholds family's progress in terms of social isues, emotional challenges and behavioral concerns through parenting education sessions. Positive parenting lures on some social learning models, information processing representations and fitness perspectives of some theoretical insights (Sanders et. al., 2003).

\subsection{Overall enquiry of the community on the effectiveness of Parenting Education Program}

A strategy for viable of a societal driven improvement community-driven develpment, and constructs the assets that are already found in the communal is a need for Asset Based Community Development (ABCD). A distinguishing measurements and set of skills in the public is to network for the improvement of the community. The beneficiaries rated the usefulness of the program very high in terms of the way and the coverage of the topics were addressed. Moreover, they equated the activities and the discussions of the relevant issues very high as information conveyed from the program facilitators as time freed of the duration of the program. This shows that enhancing the skills of the parents in educating their children by today's standards and for the future should include the use of managing situations on how they 
responded the activities based on the displayed actions. The parenting program provided meaningful learning experiences to develop assistances of controlling children and concepts of child fortification that allows them to function in the world beyond upholding children's creativity. The appropriate and successful parenting program has the potential to benefit all members in the society. Thus, the parenting education has a great bearing in interconnecting with youngsters' world.

\section{CONCLUSION}

Parenting Education Program through the direction of the CNU'S Extension's mission falls into being prepared, evidence-based and empirically certified. The results revealed that the parenting education have a great charge to deliver program which is useful and effective. These pointed out to the conclusion that the program is well-planned extension activity and evaluated with the research studies best achieve the roles as the extension service of the agency. Ample assets can incline a successful nurturing and supportive home environment because of the Extension project created by the Teacher Education Faculty. An implementing tool that proves to identify that the "EXTENSION program is at PROGRESS" to mend the existence of the children and families through an evaluating procedure of the program according to the valuation of the community respondents. Extension agencies and extension workers of parent education projects in locales such as far-flung areas have a countless accountability to provide programs that are valuable and operative.

\section{REFERENCES}

[1] Abouchaar, A. and Desforges, C. The Impact of Parental Support and Family Education on Pupil Achievements and Adjustment: A Literature Review. 2003, ISBN 1841859990.

[2] Al-Hassan, S. Evaluation of the Better Parenting Program. Report prepared for UNICEF. 2009.

[3] Altschul, I. Linking Socioeconomic Status to the Academic Achievement of Mexican American Youth through Parent Involvement in Education. 3(1), 13-30, 2012, ISSN 1948-822X

[4] Angion, Stanford E. Perceptions of marginally involved parents of academically low performing students in rural schools for increasing their involvement in their children's education. Alabama, United States: Alabama State University. 2009.

[5] Avvisati, F. et. al. Parental Involvement in School: A Literature Review. 2010.

[6] Bavolek, S. J. Nurturing Parenting Programs. 2007.

[7] Fox, R. A., \& Nicholson, B. C. Parenting young children: A facilitator's guide. Longmont, CO: Sopris West. 2003.

[8] Foxcroft, D. R. (2003). Longer-term primary prevention for alcohol misuse in young people: A systematic review. Addiction, 98, 397-411

[9] Halberstadt, A. G., Denham, S. A., \& Dunsmore, J. C. Affective social competence. Social Development, 10, 79119,2001

[10] Hodtuv, B. The correlation between the sense of empowerment of parents of young children with special needs and the degree of involvement and participation. School of Social Work, University of Tel Aviv. 2001.

[11] Perepletchikova, F., \& Kazdin, A.E. Treatment integrity and therapeutic change: Issues and research recommendations. Clinical Psychology: Science and Practice, 12(4), 356-383, 2005.

[12] Wanke, A. Parental Involvement in Children's Education. Potsdam, New York. 2008

[13] Zedan, R. Journal of Educational Enquiry Vol. 11, No. 1. 2011.

Retrieved from http://www.ojs.unisa.edu.au/index.php/EDEQ/article/viewFile/636/589

\section{BIBLIOGRAPHY OF AUTHOR}

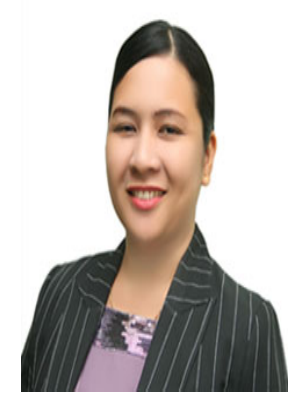

DR. JEWISH ARANETA-MERIN, is an Associate Professor III and the Quality Assurance Officer of the College of Teacher Education at Cebu Normal University. She is a proud government employee.

She raised her ranks, from Teacher I to Teacher III of the Department of Education Region 8, Division of Leyte, Matag-ob District (2002-2007) and continuously serving her Alma Mater the Cebu Normal University, Cebu City. She was one of the Dep.Ed. Regional trainees in the National English Proficiency Program (2006) and served K to 12 Basic Education Curriculum in Science (2013).

She was a recipient of several awards such as Dep. Ed Region 8 Most Outstanding Teacher District Level (2005 \& 2006), Regional Level in English and Mathematics (2005), Winning Coach Metrobank MTAP Challenge (2006), Leyte Division Pasidungog 2006 Awardee and CNU Loyalty Awardee (15yrs) as civil servant. She teaches professional subjects in the undergraduate and foundation courses in the graduate level. She is happily married to a responsible OFW Site Engr. Winston V. Merin and wonderful daughter Jewvienne Wyneth.

IJERE Vol. 7, No. 3, September 2018: 253-258 